\title{
Interface Bonding Mechanism and Mechanical Behavior of AZ31B/TA2 Composite Plate Cladded by Explosive Welding
}

\author{
Wu Jiaqi, Wang Wenxian, Cao Xiaoqing, Zhang Nan \\ Key Laboratory of Interface Science and Engineering in Advanced Materials, Ministry of Education, Taiyuan University of Technology, \\ Taiyuan 030024, China
}

\begin{abstract}
Magnesium alloys AZ31B plates and pure titanium TA2 plates were bonded successfully through explosive welding. The microstructure and composition of the interface were examined by optical microscope (OM), scanning electron microscopy (SEM) and energy dispersive spectroscope (EDS). To explore the process of element diffusion between AZ31B and TA2, the composite plates were annealed at different temperatures. Furthermore, the mechanical behavior of the composite plates was evaluated. The results show that straight and wavy interfaces coexist on the bonding area. The element diffusion becomes obvious when heating at 450 and $490{ }^{\circ} \mathrm{C}$ for 4 and 8 h. The hardness of AZ31B and TA2 is increased significantly due to the plastic deformation and the strain hardening. The mechanical properties of the composite plates are significantly improved compared with those of base plate AZ31B.
\end{abstract}

Key words: explosive welding; magnesium alloys; titanium; bonding properties

Magnesium alloys are the lightest structural metals with a density which is two-thirds of that of aluminum alloys and have high specific strength and stiffness. From a viewpoint of energy saving and fuel consumption, they are one of the high potential materials widely applied in automotive and aircraft industries. However, the application of magnesium and its alloys are still restricted because of their insufficient corrosion resistance. Hence, it is significantly important to make magnesium with other metals into laminated composite materials ${ }^{[1-3]}$. Titanium is one of the most important nonferrous metals and chemical industry materials, because of its excellent corrosion resistance and high strength ${ }^{[4]}$. Therefore, there are great hopes for creating a new type of lightweight laminated composite materials by combining magnesium alloys with titanium, which may take utilize the advantages of light metal component of magnesium and good corrosion resistance of titanium.

Nowadays, there have been a few studies describing the combination of magnesium alloys and titanium. M. Aonuma et al. ${ }^{[5]}$ investigated the microstructure and properties of magnesium alloys and titanium joint interface by friction stir welding. R. Cao et al. ${ }^{[6]}$ discussed the cold metal transfer welding-brazing of magnesium alloys AZ31B and Ti6Al4V alloys. However, there are few reports about the bonding of the two metals by the explosive welding up to now.

Explosive welding is a solid phase joining technique by which two or more materials are joined together under high pressures provided by explosive forces. In the present study, magnesium alloys AZ31B/pure titanium TA2 composite plates were fabricated by explosive welding. The microstructure and mechanical properties of the composite plates were studied and the interface bonding mechanism was clarified.

\section{Experiment}

The constituent metals used for explosive welding were magnesium alloys AZ31B and pure titanium TA2. The AZ31B were used as the base plate and TA2 as the flyer plate. The plates were degreased in acetone and ground with 600\# SiC paper in order to obtain a clean surface prior to the explosive welding. The chemical composition of AZ31B and TA2 is shown in Table 1 . In this paper, a parallel layer arrangement was used for experimental setup in the explosive welding 
process (in Fig.1).

The optical microscope observations were performed, and the interface was characterized using scanning electron microscopy (SEM). Elemental analysis of the Mg-Ti weld interface was carried out using an SEM equipped with an energy dispersive spectroscope (EDS). In order to investigate the influence of annealing on the process of element diffusion between AZ31B and TA2, the composite plate samples were annealed at 450 and $490{ }^{\circ} \mathrm{C}$ for 4 and $8 \mathrm{~h}$ in ambient atmosphere using a resistance furnace.

In order to examine the mechanical properties of AZ31B/TA2 composite plates, various mechanical tests were conducted. The shear test and the bending test were carried out for the composite plate on DNS200. The tensile test was carried out according to the ASTM: E8/E8M. The specimens were machined by a wire cut machine. To evaluate the impact toughness of the composite plates, a set of three Charpy impact test samples was prepared, in which notches were prepared on the base plate side of the composite plates. Microhardness measurement of cladding metals was carried out on HVS-1000A type microhardness test machine using $100 \mathrm{~g}$ load.

\section{Results and Discussion}

\subsection{Microstructure characterization and the bonding mechanism of interface}

Fig.2a shows the interface microstructure of the AZ31B/ TA2 composite plates. It is evident that after explosive welding, the joint of two metals is well and there are no apparent broken particles, any cracks or intermediate layer at the interface. The cladding of TA2 to AZ31B is achieved successfully by the explosive welding process. The interface morphology is mainly composed of straight interface and wave interface. Metallographic studies show that the collision between two metals is relatively homogeneous, forming a stable interface characteristic. Fig.2b shows the appearance of adiabatic shear bands (ASB) phenomenon in the AZ31B part. They incline at about $45^{\circ}$ to the explosive direction and near the interface. The ASB phenomenon is caused by the

Table 1 Chemical composition of experiment materials (wt\%)

\begin{tabular}{cccccccc}
\hline Materials & $\mathrm{C}$ & $\mathrm{O}$ & $\mathrm{Ti}$ & $\mathrm{Mg}$ & $\mathrm{Mn}$ & $\mathrm{Al}$ & $\mathrm{Fe}$ \\
\hline AZ31B & - & - & - & Bal. & 0.4 & 3.22 & 0.2 \\
TA2 & 0.01 & 0.13 & Bal. & - & - & - & 0.2 \\
\hline
\end{tabular}

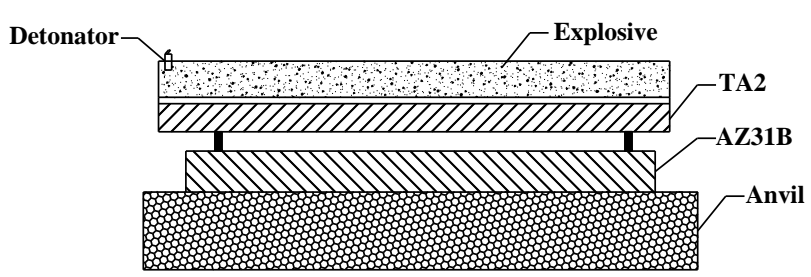

Fig.1 Schematic diagram of explosive welding process

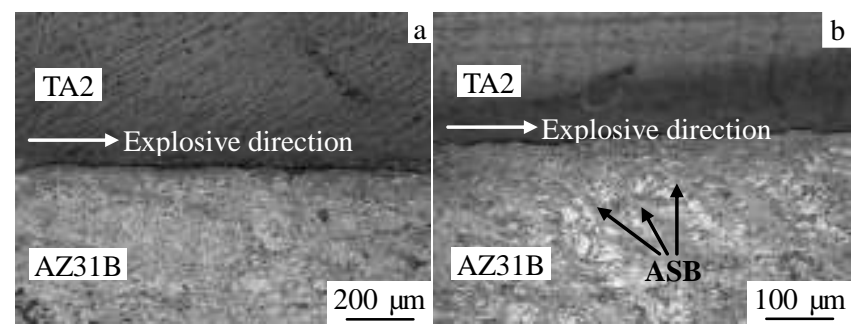

Fig.2 Structures of the interface region of the AZ31B/TA2 composite plates joint (a) and the microstructure of the AZ31B based plate (b)

severe plastic deformation under the impact of explosive ${ }^{[7]}$.

The explosive welding process creates a favorable condition for combination of metals. The process of two plates' surface bonded together under the explosion is accomplished through three stages:

(1) Physical contact stage

In the case of metals being not melted, in order to form a welded joint, it is necessary to make two surfaces be contacted tightly within the distance of $(1 \sim 5) \times 10^{-8} \mathrm{~cm}^{[8]}$. As it can be seen in Fig.2, during explosive welding, strong plastic deformation makes the oxide film of surface break and remove. They all contribute to eliminating the barrier for the atoms contact. Under this advantageous condition, the atoms close to each other under the explosive pressure and the physical contact is obtained.

(2) Chemical interaction stage

Mechanical bond formed by surface physical contact could not provide a strong connection between atoms. In order to obtain strong connection, the atoms of the surface must be activated. Because of the plastic deformation of AZ31B/TA2 interface, there are some metallographic defects in the interface or grain boundary and these defects may cause lattice distortion. The energy of the atoms increases significantly in these areas, which results in high pulsed frequency of atoms ${ }^{[9]}$. Then the activation of the contact surface and the center is formed. In the end, the chemical interaction between two welding surfaces is produced to form the chemical bond. As a result, the bonding strength of composite plates is improved finally.

(3) Volumetric interaction stage

The essence of this stage is that the elements of metals diffuse to the surrounding metal materials. According to the Ficks' first law:

$$
J=-D \frac{\partial C}{\partial x}
$$

Where $J$ is the diffusion flux, $D$ is the diffusivity and $\frac{\partial C}{\partial x}$ is the concentration gradient of both sides of the interface. During the explosive welding of AZ31B/TA2 composite plate, there is a significant gradient of element concentration at the interface. This sharp transition of concentration gradient made 
a contribution to the diffusion in the explosive welding process. However, the diffusivity $D$ is given by:

$$
D=D_{0} \exp (-\Delta E / k T)
$$

Where $D_{0}$ is the diffusivity coefficient, $\Delta E$ is the activation energy of diffusion, $k$ is the gas constant and $T$ is the absolute temperature. It reveals that the plastic deformation occurs under high pressure and high temperature during the explosive welding process. Furthermore, the thermal motion of atoms increases and then affects the diffusivity. Thus, it made a contribution to the diffusion of elements on the interface.

As shown in Fig.3, the bonding interface produces "trunklike" structure and vortexes. During the process of explosive welding, flyer plate TA2 collides with the base plate AZ31B at a high velocity, and a great pressure is loaded at the collision point. Under this special condition, TA2 suffers a plastic deformation intensely. When the plastically deformed TA2 inserts into the AZ31B, the base plate would be depressed and form the valley, and then the trunks appear. The same phenomenon has been reported in the previous study. Xia et al. ${ }^{[10]}$ reported that the "trunk" was located on the crest front along the detonation direction and the vortex was caused by the heat of plastic deformation. It confirms that the plastic deformation exist on both sides of the substrate.

\subsection{Influence of heat treatment on the element diffusion}

The SEM morphology observation and the EDS line analysis across the interface of the AZ31B/TA2 composite plates after heat treatment were conducted. The interfacial transition zone of the sample annealing at 450 and $490{ }^{\circ} \mathrm{C}$ for $4,8 \mathrm{~h}$ has a significant change compared with that of explosion state. And the SEM micrographs and element distribution of the AZ31B/TA2 composite plates interface are given in Fig.4 and Fig.5, respectively. As it can be seen from Fig.5, a certain degree of diffusion of $\mathrm{Mg}$, Ti and $\mathrm{Al}$ elements happens on the interface. By increasing the annealing temperature and holding time, the thickness of the diffusion layer is increased considerably. According to Eq.(2), the thickness of the diffusion layer is slightly thicker than that under the explosive condition, which is responsible for the increase of the elements diffusion coefficient and rate resulted from the higher annealing temperature. According to $\mathrm{Mg}-\mathrm{Ti}$ binary phase diagram ${ }^{[11]}$, the solid solubility of $\mathrm{Mg}$ in titanium

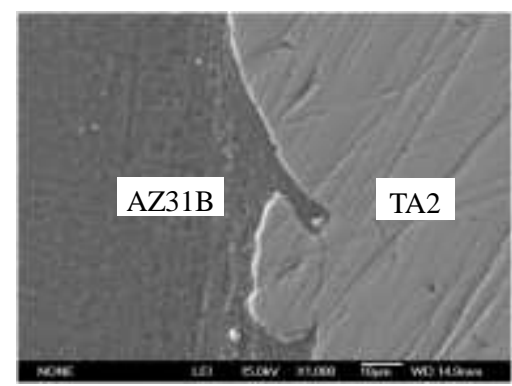

Fig.3 SEM image of the interface region showing formation of "trunk-like" structure and vortexes is less than 2at\%, while the solid solubility of $\mathrm{Ti}$ in magnesium is less than $0.1 \mathrm{at} \%$. Hence, $\mathrm{Mg}$ and $\mathrm{Ti}$ could not obtain high diffusion coefficient at this temperature. However, $\mathrm{Al}$ element as the transition element plays an important role in the diffusion between $\mathrm{Mg}$ element and $\mathrm{Ti}$ element ${ }^{[12]}$. Furthermore, this conclusion could also be proved by the content of $\mathrm{Al}$ element approaching the peak value in the transition zone between the interface of AZ31B and TA2 in Fig.5. As shown in Fig.5, in the interface layer, Ti decreases and $\mathrm{Mg}$ increases gradually from TA2 to AZ31B. An obvious $\mathrm{Al}$ concentration is found in the interface layer, which indicates that some $\mathrm{Mg}-\mathrm{Al}$ or $\mathrm{Ti}-\mathrm{Al}$ intermetallic compounds are likely to be formed because the $\mathrm{Al}$ can react with both $\mathrm{Ti}$ and $\mathrm{Mg}$. Aonuma et al. ${ }^{[5]}$ have found that a thin Al-rich layer was partly detected on the joint interface of the AZ61A/Ti and AZ91D/Ti interfaces, a Ti-Al intermetallic compound layer was observed clearly on the joint interface.

\subsection{Mechanical properties}

\subsubsection{Microhardness test}

Fig.6 shows the microhardness profile across the AZ31B/ TA2 bonding interface after explosive welding. The results indicate that the microhardness of both materials increases significantly in comparison to the original ones, which implies that the microstructure near the interface is modified by the high degree of plastic deformation resulting from the collision of plates. On the TA2 side, it is evident that the microhardness increases significantly near the bonding interface and approaches a peak value due to the high density of dislocations and strain hardening effect. The microhardness value, then decreases to $1030 \mathrm{MPa}$ at the distance about $26 \mu \mathrm{m}$ away from the interface. The accumulation of stress due to the difference in the coefficient of thermal expansion between AZ31B and TA2 leads to the hardening effect. On the AZ31B side, the microhardness increases slightly near the bonding interface. The

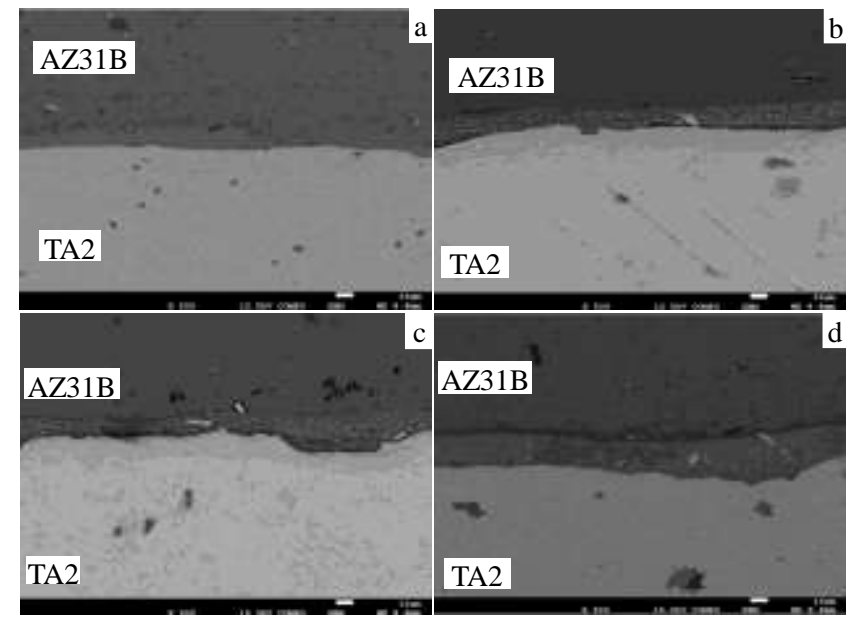

Fig.4 SEM images of AZ31B/TA2 composite plate interface after annealing at $450{ }^{\circ} \mathrm{C} / 4 \mathrm{~h} \mathrm{(a),} 450{ }^{\circ} \mathrm{C} / 8 \mathrm{~h}(\mathrm{~b}), 490{ }^{\circ} \mathrm{C} / 4 \mathrm{~h}$ (c), and $490{ }^{\circ} \mathrm{C} / 8 \mathrm{~h}(\mathrm{~d})$ 

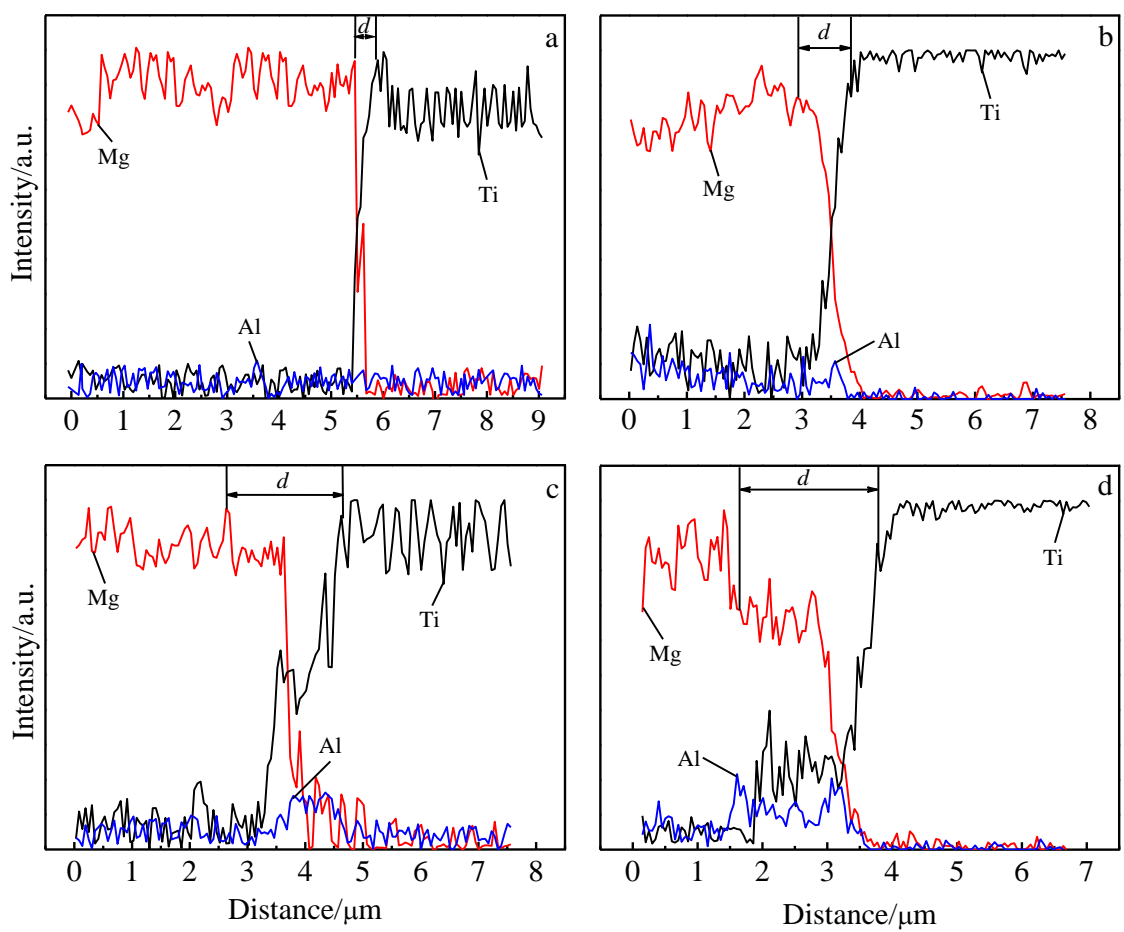

Fig.5 EDS elements distribution profiles of $\mathrm{Mg}$, $\mathrm{Ti}$, and $\mathrm{Al}$ across the interface from specimens of composite plate after annealing at $450{ }^{\circ} \mathrm{C} / 4 \mathrm{~h} \mathrm{(a)}, 450{ }^{\circ} \mathrm{C} / 8 \mathrm{~h}(\mathrm{~b}), 490^{\circ} \mathrm{C} / 4 \mathrm{~h}(\mathrm{c})$, and $490{ }^{\circ} \mathrm{C} / 8 \mathrm{~h}(\mathrm{~d})(d=$ thickness of diffusion layer)

decrease of the hardness at the TA2 side close to the bonding interface is the result of overaging of TA2 due to the temperature rise induced by high velocity oblique collision. Mastanaiah et al. ${ }^{[13]}$ reported that the peak hardness observed at the bond line could be attributed to the high degree of deformation during the explosive welding operation.

\subsubsection{Charpy impact toughness test}

In order to research the notch toughness of the composite metals, the Charpy impact test was carried out at room temperature. The test results are summarized in Table 2. The results show that the impact energy of composite plates is 12.71 $\mathrm{J} \cdot \mathrm{cm}^{-2}$ at room temperature, which is higher than $4.81 \mathrm{~J} \cdot \mathrm{cm}^{-2}$ of the magnesium alloys AZ31B sheet ${ }^{[14]}$. It indicated that the impact energy of AZ31B/TA2 composite plates is improved

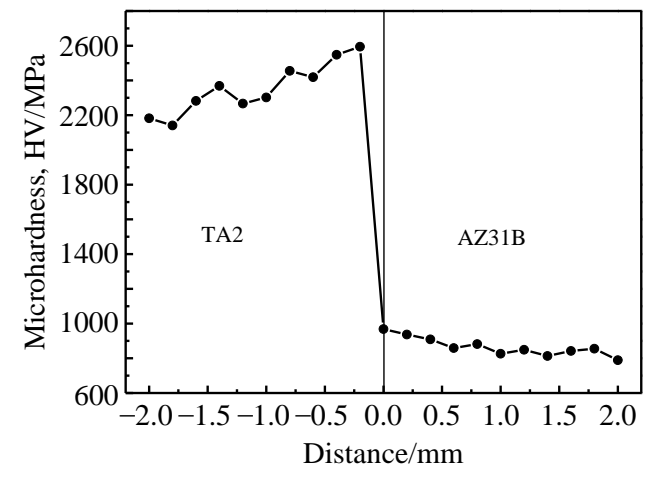

Fig.6 Microhardness profile across the AZ31B/TA2 bonding interface after explosive welding
Table 2 Results of Charpy impact test

\begin{tabular}{cccc}
\hline \multirow{2}{*}{ Test number } & \multirow{2}{*}{ Test temperature $/{ }^{\circ} \mathrm{C}$} & \multicolumn{2}{c}{ Impact energy, $A_{\mathrm{kv}} / \mathrm{J} \cdot \mathrm{cm}^{-2}$} \\
\cline { 3 - 4 } & & Test value & Average value \\
\hline 1 & 20 & 14.92 & \\
2 & 20 & 10.35 & 12.71 \\
3 & 20 & 12.88 & \\
\hline
\end{tabular}

significantly after explosive welding.

The toughness and the ability to absorb shock loads of titanium is higher than that of magnesium alloys. Fig.7 shows the particular macro-fracture morphology of the sample: when the crack propagates from AZ31B plate to the bonding interface, it does not propagate through the bonding interface to the TA2 plate immediately. It extends along the interface to both sides instead, and finally reaches the TA2 plate until the composite plate fracture. This fracture process allows the composite plates to resist crack propagation with relatively high energy absorption. As a result, it improves the impact resistance of the AZ31B/TA2 composite plates.

\subsubsection{Shear test}

The shear test was conducted on the explosive welding samples to obtain the bond strength. The images of samples after shear-tensile test are depicted in Fig.8a. The crack firstly occurs on one side of the bonding interface under the shear force. With the load increase, the crack propagates along the bonding interface and results in the separation of composite plates at the bonding interface finally. The shear strengthdisplacement curve in Fig.8b indicates that the shear strength 


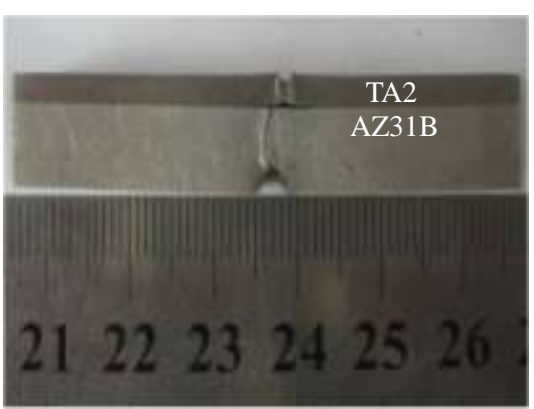

Fig.7 Fracture macrograph of specimen after impact test

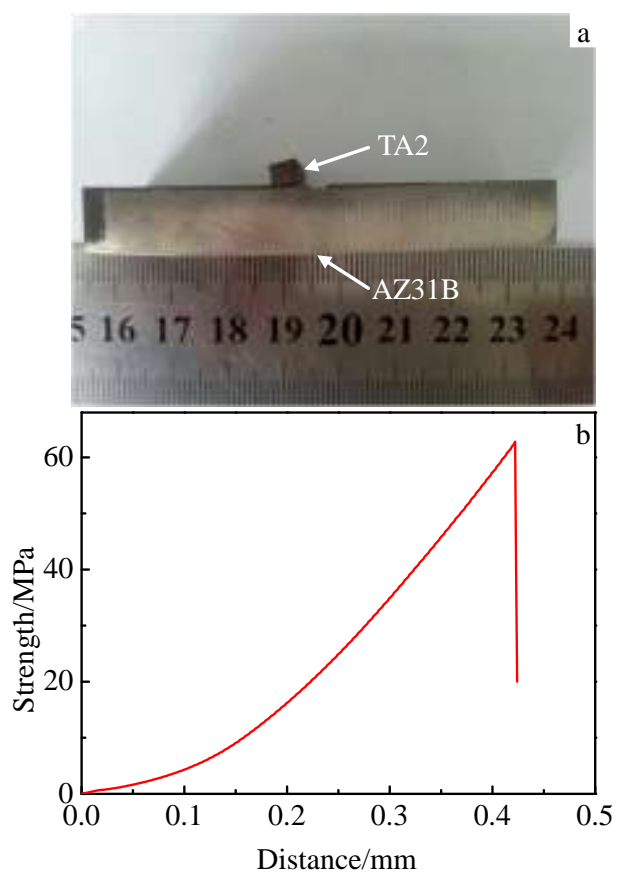

Fig.8 Failure macrograph of the specimen (a) and strengthdisplacement curve of the AZ31B/TA2 composite plate (b) after shear-tensile test

of AZ31B/TA2 composite plates is approximately $64 \mathrm{MPa}$. There is no obvious yield stage in the process of fracture. It means that the fracture process presents the characteristic of brittle fracture.

\subsubsection{Bending test}

In order to determine the delamination resistance of the welding interface, bending properties of the explosively welded TA2/AZ31B composite plate was investigated. Fig.9 shows the macrographs of the composite plate after bending test. It illustrates that the composite plate has the high delamination resistance. The part of AZ31B cracks firstly due to the bad deformation properties. No debonding is observed. It also indicates the well bonding properties.

\subsubsection{Tensile test}

A typical experimental curve of strain-stress relationship during tension testing is shown in Fig.10a. There are two
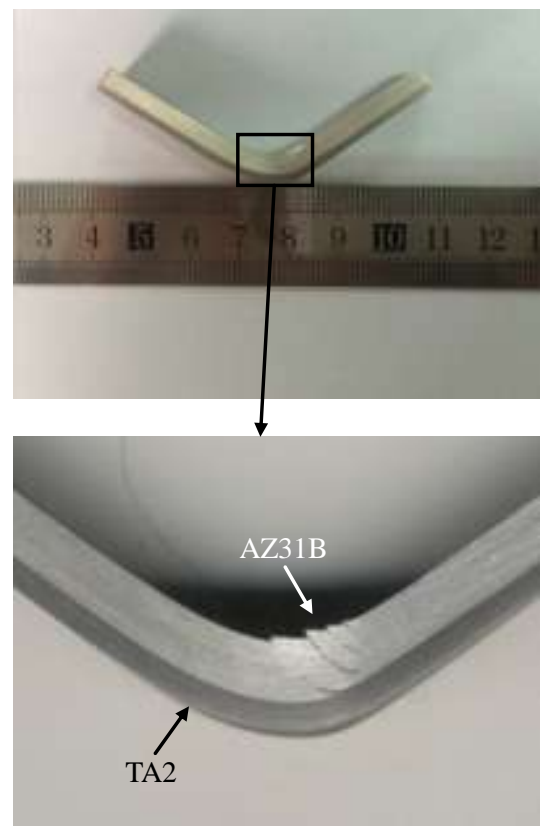

Fig.9 Morphologies of the composite plate after three-point bending test

abrupt turns in the curve, which correspond to the successive fracture of the individual plates. The first abrupt turn is due to the fracture of AZ31B while the second one occurs due to the fracture of TA2, Since the tensile strength of TA2 is better than AZ31B ${ }^{[15]}$. The macroscopic morphology of the composite plate after fracturing is demonstrated as Fig.10b. The ultimate tensile strength of the composite plate is about 264 $\mathrm{MPa}$, which is higher than that of AZ31B. The tensile property of the composite plate is better than that of the base plate
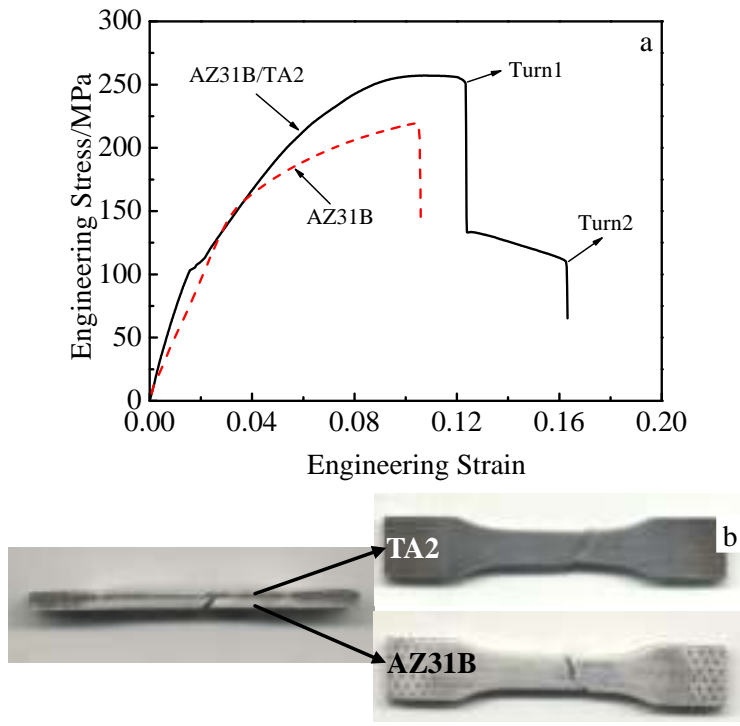

Fig.10 Typical stress-strain curvesof the $\mathrm{Mg} / \mathrm{Ti}$ composite plate (a) and the fractured sample produced by the tensile test (b) 
$\mathrm{Mg}$. It suggests that the mechanical property of the base plate $\mathrm{Mg}$ is improved by bonding the Ti plate. The good tensile strength depends on the effective bonding property.

\section{Conclusions}

1) The AZ31B/TA2 composite plate is fabricated successfully by explosive welding and the interface morphology is mainly composed of straight interface and wave interface. $\mathrm{Mg}$ and $\mathrm{Ti}$ elements diffuse slightly at bonding interface. With increasing of the annealing temperature and holding time, the diffusion degree of elements on the interface improves significantly.

2) The morphology of welding area is formed by the irreversible plastic deformation process of metals under explosion load. The plastic deformation results in the appearance of three stages which include the formation of the physical contact stage, chemical interaction stage and volumetric interaction stage.

3) The high degree of plastic deformation results from the collision of plates. The hardness of both materials increases greatly in comparison to that of the original ones.

4) The tensile strength of AZ31B/TA2 composite plates is about $264 \mathrm{MPa}$. The shear strength is approximately $64 \mathrm{MPa}$. The impact resistance and bending properties of the composite plates are remarkably higher than that of the AZ31B component alone.

\section{References}

1 Hirsch J, Al-Samman T. Acta Mater[J], 2013, 61: 818
2 Liu F C, Liang W, Li X R et al. Journal of Alloys and Compound [J], 2008, 461(1-2): 399

3 Joseph F M, Senthilkumar T, Balasubramanian V et al. Materials \& Design[J], 2012, 33: 31

4 Casalino G, Curcio F. Journal of Materials Processing Technology[J], 2005, 167(2-3): 422

5 Aonuma M, Nakata K. Materials Science and Engineering B[J], 2009, 161(1): 46

6 Cao R, Wang T, Wang C et al. Journal of Alloys and Compound [J], 2014, 605: 12

7 Yan Y B, Zhang Z W, Shen W et al. Materials Science and Engineering $A[J], 2010,527(9): 2241$

8 Akbari M S A A, Barrett L M, Alhassani S T S. Journal of Materials Processing Technology[J], 2008, 202(1-3): 224

9 Raghukandan K. Journal of Materials Processing Technology[J], 2003, 139(1-3): 573

10 Xia H B, Wang S G, Ben H F. Materials \& Design[J], 2014, 56(4): 1014

11 Liu C M, Zhu X R, Zhou H T. Phase Diagrams of Magnesium Alloys[M]. Changsha: Central South University Press, 2000: 56

12 Gao M, Wang Z M, Li X Y et al. Metallurgical and Materials Transactions A[J], 2012, 43(1): 163

13 Mastanaiah P, Reddy G M, Prasad K S et al. Journal of Materials Processing Technology[J], 2014, 214(11): 2316

14 Zhang Hongxia, Wang Wenxian, Su Juan et al. Rare Metal Materials and Engineering[J], 2009, 38(S3): 186 (in Chinese)

15 Kacar R, Acarer M. Journal of Materials Processing Technology [J], 2004, 152(1): 91

\title{
AZ31B/TA2 爆炸焊接复合板界面结合机制及力学性能
}

\author{
武佳琪，王文先，曹晓卿，张 楠 \\ (太原理工大学 新材料界面科学与工程教育部重点实验室, 山西 太原 030024)
}

\begin{abstract}
摘 要: 镁合金 AZ31B 和纯钛 TA2 通过爆炸焊接的方法成功实现了连接。采用光学显微镜(OM)、扫描电镜(SEM)、以及能谱(EDS)等 测试手段对结合界面的微区结构、元素分布进行了分析。研究了在不同温度热处理后 AZ31B 和 TA2 界面之间元素的扩散情况。同时结 合显微硬度实验、冲击试验、拉伸试验研究了复合板的力学性能。并对复合板的结合机制进行了一定的探讨。结果表明：平直和波浪状 结合形貌并存于结合界面。在热处理温度为 450 和 $490{ }^{\circ} \mathrm{C}$ 、保温时间为 4 和 $8 \mathrm{~h}$ 时, 界面元素扩散明显。由于两侧金属发生塑性变形导 致界面硬度升高。复合板的各种力学性能均较基板 AZ31B 镁合金得到了一定程度的提高。
\end{abstract}

关键词：爆炸焊接；镁合金；纯钛；结合特性

作者简介: 武佳琪, 女, 1989 年生, 硕士, 太原理工大学材料科学与工程学院, 山西 太原 030024, 电话: 0351-6010076, E-mail: tylgzn@163.com 